Development and Implementation of a Pilot Registry for Monitoring the Efficacy and Safety of Novel Therapies in Patients with Systemic Lupus Erythematosus

Christina Adamichou, Irini Flouri, Antonios Fanouriakis, Myrto Nikoloudaki, Dionysios Nikolopoulos, Argyro Repa, Kyriaki Boki, Katerina Chatzidionysiou, Alexandros Garyfallos, Dimitrios Boumpas, Prodromos Sidiropoulos, George Bertsias

Mediterr J Rheumatol 2020;31(1):87-91

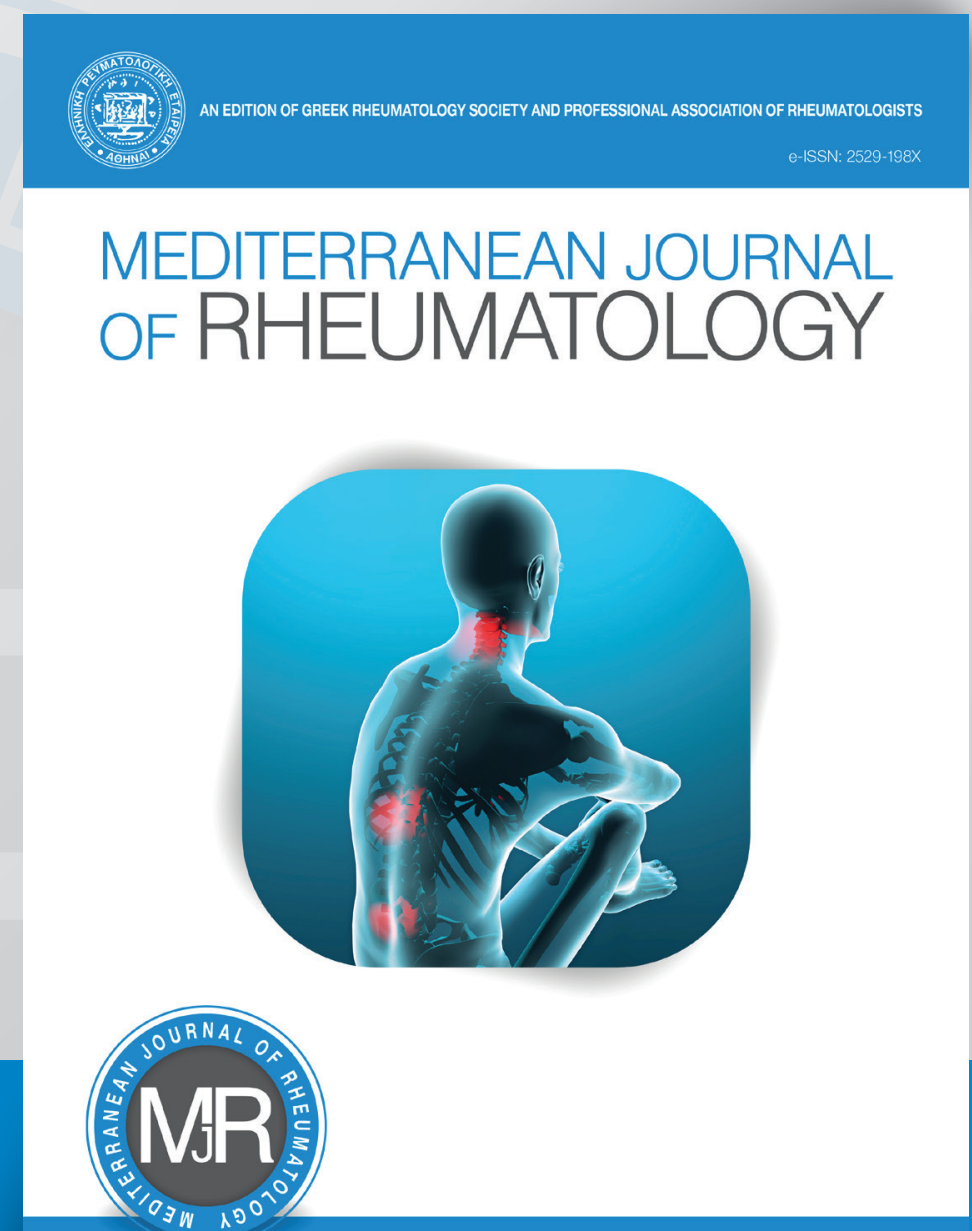




\section{Development and Implementation of a Pilot Registry for Monitoring the Efficacy and Safety of Novel Therapies in Patients with Systemic Lupus Erythematosus}

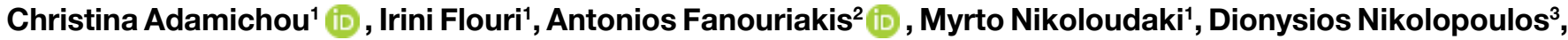 Argyro Repa', Kyriaki Boki ${ }^{4}$, Katerina Chatzidionysiou ${ }^{5,6}$, Alexandros Garyfallos ${ }^{7}$, Dimitrios Boumpas ${ }^{3}$ (iD , Prodromos Sidiropoulos $^{1}$ (D) , George Bertsias ${ }^{1}$}

${ }^{1}$ Rheumatology and Clinical Immunology, University of Crete Medical School and University Hospital of Heraklion, Heraklion, Greece, ${ }^{2}$ Rheumatology Clinic, General Hospital of Athens "Asklepeion Voula", Athens, Greece, ${ }^{3}$ Rheumatology Clinic, 4 $4^{\text {th }}$ Department of Internal Medicine, National and Kapodistrian University of Athens, "Attikon" University Hospital, Athens,Greece, ${ }^{4}$ Rheumatology Clinic, "Sismanogleio" General Hospital, Athens, Greece, ${ }^{5}$ First Department of Propaedeutic Internal Medicine, National and Kapodistrian University of Athens, "Laiko" General Hospital, Athens, Greece, ${ }^{6}$ Department of Medicine, Solna, Rheumatology Unit, Karolinska University Hospital and Institutet, Stockholm, Sweden, ${ }^{7} 4^{\text {th }}$ Department of Internal Medicine, Hippokration General Hospital, School of Medicine, Aristotle University of Thessaloniki, Thessaloniki, Greece

\section{ABSTRACT}

The therapeutic armamentarium in Systemic Lupus Erythematosus (SLE) is expanding with the introduction of novel biologic and small-molecule agents. Complementary to randomized controlled trials, registry-based studies are advantageous due to the inclusion of a wider range of patients from daily practice and the potential for long-term monitoring of the efficacy and safety of therapies. Moreover, data from registries can be used to identify disease phenotypes that best respond to biologic agents, and to correlate clinical response with parameters such as co-administered therapies and comorbidities. In this project, we will use the configuration of the Hellenic Registry of Biologic Therapies for inflammatory arthritides in order to design a dedicated SLE module with variables pertaining to global and organ-specific disease activity, severity, flares, organ damage/ outcome, comorbidities and adverse events. The second stage will involve the pilot implementation

\section{BACKGROUND AND STUDY RATIONALE}

Systemic lupus erythematosus (SLE) encompasses a wide range of clinical and immunological manifestations, which makes monitoring of patients and assessment of their response to therapy a challenging task. ${ }^{1}$ For many years, treatment of SLE was based primarily on the administration of corticosteroids and non-specific immu-

\section{Corresponding Author:}

George Bertsias

Rheumatology and Clinical Immunology, University of Crete Medical School

71003 Voutes Campus, Iraklio, Greece

Tel.: +30 2810394635

Fax: +302810394636

E-mail: gbertsias@uoc.gr achieve long-standing remission. ${ }^{2}$ Importantly, conventional drugs, particularly corticosteroids, are associated with excessive toxicity risks, accrual of comorbidities and irreversible end-organ damage. ${ }^{3}$

Scientific advancements in our understanding of the immunopathogenesis of SLE, coupled with better-designed clinical studies, ${ }^{4}$ have led to the expansion of the therapeutic armamentarium due to repositioning of drugs administered in other medical conditions (eg, mycophenolate ${ }^{5}$ ) and the increasing use of approved (e.g. belimumab6) and non-approved (eg, rituximab7) biologic agents. Based on the findings of recently performed controlled trials, ,-14 $^{8-14}$ a number of innovative therapies in SLE, including monoclonal antibodies (eg, anifrolumb, ustekinumab, obinutuzumab) and small molecules (eg, Janus kinase inhibitors), are expected to be introduced in the near future. 
of this platform for the multicentric registration of SLE patients who are treated with belimumab. The significance lies in the development of a structured registry that enables the assessment of the disease burden and the long-term efficacy and safety of existing and future biological agents in SLE. Piloting the registry can serve as a basis for establishing nationwide collaborative efforts.

Mediterr J Rheumatol 2020;31(1):87-91

https://doi.org/10.31138/mjr.31.1.87

Article Submitted: 15 Jan 2020; Article Accepted: 02 Feb 2020; Published: 31 Mar 2020

Keywords: registry, biological agents, novel therapies, belimumab, rituximab, systemic lupus erythematosus

Post-marketing analysis of the efficacy and safety of new drugs is important in defining their application in routine clinical practice. In addition to the results from randomized clinical trials (RCTs), a significant amount of information can be derived from patient registries that systematically assess the effects of treatments under "real-life" conditions. Registries are also advantageous because they allow the inclusion of a wide spectrum of patients without the stringent exclusion criteria of RCTs (eg, patients with co-morbidities or less frequent disease manifestations), and monitoring for long-term drug efficacy and safety (including rare adverse events). ${ }^{15,16}$ In the case of SLE, which is a multifaceted, systemic autoimmune disease, data from organized patient registries may be particularly useful to approach clinically-relevant issues that cannot be easily addressed through clinical trials. These may include, for instance, the definition of disease endo-phenotypes that respond better to individual treatments, and the association between drug efficacy/safety with various disease parameters (co-administered treatments, comorbidities, etc.). Furthermore, collected data may help to obtain unique insights into the mechanisms of action of novel therapies.

The value of establishing registries of patients receiving biological agents has been illustrated in inflammatory arthritides (rheumatoid arthritis, spondyloarthritis). Thus, analysis of registry-derived data has shed light on topics such as the identification of clinical factors that are predictive of treatment response, the safety of biologics in terms of the risk for latent infections and malignancies, the use of sequential therapies ('switches'), the main causes of drug discontinuations and other. ${ }^{17-20}$ Likewise, large SLE registries, such as the Johns Hopkins Lupus Cohort, have provided significant knowledge with regards to the dose-dependent corticosteroid toxicity and the role of hydroxychloroquine in prevention of disease flare-ups. ${ }^{1,3}$ Another example is the British Isles Lupus Assessment Group (BILAG) Biologics Register of SLE patients, which has described the main features of patients who are candidates for biological treatment and has investigated the short-term efficacy and safety associated with the use of rituximab. ${ }^{7}$

To date, there is no structured platform for registering SLE patients in Greece under biologic therapies, and, accordingly, there is paucity of data on the indications, long-term efficacy and safety of these agents in real-life clinical settings. In this study, we seek to establish and implement a pilot system for the electronic registration and monitoring of patients with SLE who are treated with existing biologic but also, future novel therapeutics agents.

\section{AIMS OF THE STUDY}

The aim of the present study is to establish and run a pilot study of an electronic registry for monitoring SLE patients who are treated with novel/biologic therapies. The study has multicentric, prospective design with two implementation stages.

\section{METHODS \\ Study design}

This is a prospective study that will be performed at the Rheumatology Clinic, University of Crete Medical School and University Hospital of Heraklion (involved at stages I and II of the protocol) in collaboration with the Rheumatology Units/Clinics of the "Attikon" University Hospital, "Laiko" General Hospital, General Hospital of Asklepieion Voula, Hippokration University Hospital of Thessaloniki, and "Sismanogleio" General Hospital (involved at stage II of the protocol). The study has been approved by the Ethics Committees of the participating centers.

The first stage (0-6 months) of the protocol includes the design of a specialized electronic platform (registry) for patients with SLE. The development of the registry will be based on the configuration and software of the existing registry of patients with chronic inflammatory arthritides who are treated with biologic agents (University of Crete, Medical School), ${ }^{17}$ following amendments to capture at each visit: the dosage of main and secondary treatments, 
general and organ-specific indices of SLE disease activity, flares, organ damage, health-related quality of life and functional status, comorbidities, adverse events and causes of drug discontinuation (outlined below).

The second stage (7-30 months) of the protocol will include the pilot use of the electronic registry for the multicentric enrolment and longitudinal monitoring of patients who meet the following inclusion criteria: a) fulfil at least one of the three classification criteria (ACR 1997, ${ }^{21}$ SLICC 2012,22 EULAR/ACR 201923) for SLE, and b) already receive or are started on belimumab, which represents the single approved biologic agent in SLE. ${ }^{24}$ We also plan to update the long-term efficacy and safety data of a previously published cohort of patients. ${ }^{6}$ We will assess the effectiveness (both globally and across individual organs/domains), attainment of low disease activity and remission states, the co-administration of glucocorticoids and other treatments, major events (comorbidities) and adverse events (outlined below).

\section{Design of the electronic registry}

An online software is under development at the Rheumatology Clinic, University of Crete Medical School, in collaboration with the Centre for eHealth Applications and Services (CeHA) at the Institute of Computer Science, Foundation for Research and Technology - Hellas (ICS-FORTH) (http://web-new.ics.forth.gr/ceha/). This is a web-based platform with secure connection, anonymised entry of patient data, encrypted data storage in line with the General Data Protection Regulation (GDPR) and ability to export selected data for further analysis. The SLE registry module will be based on the structure and configuration of the Hellenic Registry of Biologic Therapies for patients with inflammatory arthritides. ${ }^{17}$

\section{Registry variables}

From each patient, the following variables will be collected at inclusion visit (initiation of treatment) and/or at regular (6-month) follow-up intervals:

- Demographics (gender, nationality, date of birth)

- Date of diagnosis

- SLE classification criteria (ACR 1997, ${ }^{21}$ SLICC 2012,, EULAR/ACR 201923)

- Disease stratification (mild, moderate, severe) based on BILAG-defined organ activity, ${ }^{25,26}$ administration of corticosteroids and use of potent immunosuppressive/ cytotoxic or biologic treatments

- Disease activity pattern (relapsing-remitting, chronic active)

- Global activity indices (SLEDAI-2000, ${ }^{27}$ Physician Global Assessment [PhGA] ${ }^{28}$ )

- Organ-specific activity indices (CLASI index for cutaneous lupus, ${ }^{29}$ tender and swollen joint counts, proteinuria, Likert scale for neurological deficits)

- Disease flares (SELENA-SLEDAI Index ${ }^{28}$ )
- Definitions of Lupus Low Disease Activity State (LLDAS) ${ }^{30}$ and remission ${ }^{31}$

- Irreversible organ damage (SLICC/ACR Damage Index ${ }^{32}$ )

- Functional status (Health assessment questionnaire disability index $\left.[\mathrm{HAQ}-\mathrm{DI}]^{33}\right)$

- Comorbidities (Rheumatic Disease Comorbidity Index $\left.[\mathrm{RDCl}]^{34}\right)$

- Treatments (previous, ongoing): detailed record of medications (main treatment, concomitant disease treatments) and administered forms/dosage

- Adverse reactions and events (MedDRA recording system; https://www.meddra.org/faq/meddra-general), treatment discontinuations

\section{Data entry and collection}

Each participating centre will be granted access to the electronic platform (registry) with unique credentials in order to enter their own patient data. As this is a pilot implementation of the registry, we aim to enrol a total of 60 SLE patients under treatment with belimumab, which will allow to obtain statistically robust results.

\section{Statistical analysis}

A single export of merged patient data from all centres will be obtained for statistical analysis (months 31-36). Descriptive results on demographics, proportion of patients with partial or complete clinical response, attainment of LLDAS and remission/flares will be calculated. Efficacy will be correlated with baseline clinical and demographic characteristics. Safety will be assessed according to occurrence of major events. Treatment survival and reasons for discontinuation will also be evaluated.

\section{ANTICIPATED RESULTS AND PROJECT SIGNIFICANCE}

Registries of patients with chronic rheumatic diseases receiving biological therapies have provided significant insights regarding their long-term efficacy and safety in "real-life" clinical practice. In recent years, biological agents such as belimumab and rituximab have been introduced in the treatment of SLE, and based on the results from ongoing clinical trials, it is likely that additional innovative therapies may be added in the near future.

The importance of this project lies in the development and pilot use of a dedicated electronic registry of patients with SLE who are treated with novel/biologic therapies, which will enable the detailed monitoring of drug efficacy and safety by the use of validated clinical instruments (eg, SLEDAl-2000, CLASI, RDCl, MedDRA). Moreover, the registry will help to assess the burden of the disease (severe lupus, flares, organ damage, comorbidities) among contemporary SLE patients who are seen at large Rheumatology Centres in Greece, as well as the long-term retention rates of the biological agents used in SLE such as belimumab. Importantly, the successful pilot implemen- 
tation of the registry could pave the way for establishing broader collaborative projects at a national level.

\section{FUNDING}

This study is funded in by the Pancretan Health Association and by the Hellenic Society of Rheumatology and Professionals Union of Rheumatologists of Greece (protocol number 852).

\section{CONFLICTS OF INTEREST}

The authors declare no conflicts of interest.

\section{REFERENCES}

1. Adamichou C, Bertsias G. Flares in systemic lupus erythematosus: diagnosis, risk factors and preventive strategies. Mediterr J Rheumatol 2017;28:4-12. [https://doi.org/10.31138/mjr.28.1.4]

2. Fanouriakis $A$, Bertsias $G$. Changing paradigms in the treatment of systemic lupus erythematosus. Lupus Sci Med 2019;6:e000310. [https://doi.org/10.1136/lupus-2018-000310] [PMID: 31168398] [PMCID: PMC6519431]

3. Al Sawah S, Zhang X, Zhu B, Magder LS, Foster SA, likuni N, et al. Effect of corticosteroid use by dose on the risk of developing organ damage over time in systemic lupus erythematosus-the Hopkins Lupus Cohort. Lupus Sci Med 2015;2:e000066. [https:// doi.org/10.1136/lupus-2014-000066] [PMID: 25861455] [PMCID: PMC4378372]

4. Dorner T, Furie R. Novel paradigms in systemic lupus erythematosus. Lancet 2019;393:2344-58. [https://doi.org/10.1016/S01406736(19)30546-X] [PMID: 31180031]

5. Tselios K, Gladman DD, Su J, Urowitz MB. Mycophenolate Mofetil in Nonrenal Manifestations of Systemic Lupus Erythematosus: An Observational Cohort Study. J Rheumatol 2016;43:552-8. [https:// doi.org/10.3899/jrheum.150779] [PMID: 26773121]

6. Fanouriakis A, Adamichou C, Koutsoviti S, Panopoulos S, Staveri C, Klagou A, et al. Low disease activity-irrespective of serologic status at baseline-associated with reduction of corticosteroid dose and number of flares in patients with systemic lupus erythematosus treated with belimumab: A real-life observational study. Semin Arthritis Rheum 2018;48:467-74. [https://doi.org/10.1016/j. semarthrit.2018.02.014] [PMID: 29555348]

7. McCarthy EM, Sutton E, Nesbit S, White J, Parker B, Jayne D, et al. Short-term efficacy and safety of rituximab therapy in refractory systemic lupus erythematosus: results from the British Isles Lupus Assessment Group Biologics Register. Rheumatology (Oxford) 2018;57:470-9. [https://doi.org/10.1093/rheumatology/kex395] [PMID: 29216396] [PMCID: PMC5850287]

8. GlaxoSmithKline. https://www.gsk.com/en-gb/media/press-releases/gsk-announces-positive-headline-results-in-phase-3study-of-benlysta-in-patients-with-lupus-nephritis/. Accessed 2019.

9. Morand EF, Furie R, Tanaka Y, Bruce IN, Askanase AD, Richez C, et al. Trial of Anifrolumab in Active Systemic Lupus Erythematosus. N Engl J Med 2020;382:211-21. [https://doi.org/10.1056/NEJMoa1912196] [PMID: 31851795]

10. Rovin BH, Solomons N, Pendergraft WF 3rd, Dooley MA, Tumlin J, Romero-Diaz J, et al. A randomized, controlled double-blind study comparing the efficacy and safety of dose-ranging voclosporin with placebo in achieving remission in patients with active lupus nephritis. Kidney Int 2019;95:219-31. [https://doi.org/10.1016/j. kint.2018.08.025] [PMID: 30420324]

11. Schindler T, Rovin B, Furie R, Leandro M, Clark M, Brunetta $P$, et al. AB0423 Nobility, A Phase 2 Trial To Assess The Safety and Efficacy of Obinutuzumab, A Novel Type 2 Anti-CD20 Monoclonal Antibody (MAB), in Patients (PTS) with ISN/RPS Class III or IV Lupus Nephritis (LN). Ann Rheum Dis 2016;75:1051.2-1051. [https:// doi.org/10.1136/annrheumdis-2016-eular.2397]
12. van Vollenhoven RF, Hahn BH, Tsokos GC, Lipsky P, Fei K, Gordon RM, et al. Maintenance of efficacy and safety of ustekinumab through 1 year in a randomized phase II trial of patients with active systemic lupus erythematosus. Arthritis Rheumatol 2019. [https:// doi.org/10.1002/art.41179] [PMID: 31769212]

13. van Vollenhoven RF, Hahn BH, Tsokos GC, Wagner CL, Lipsky P, Touma Z, et al. Efficacy and safety of ustekinumab, an IL-12 and IL23 inhibitor, in patients with active systemic lupus erythematosus: results of a multicentre, double-blind, phase 2, randomised, controlled study. Lancet 2018;392:1330-9. [https://doi.org/10.1016/ S0140-6736(18)32167-6] [PMID: 30249507]

14. Wallace DJ, Furie RA, Tanaka Y, Kalunian KC, Mosca M, Petri MA, et al. Baricitinib for systemic lupus erythematosus: a double-blind, randomised, placebo-controlled, phase 2 trial. Lancet 2018;392:222-31. [https://doi.org/10.1016/S01406736(18)31363-1] [PMID: 30043749]

15. Finckh A, Courvoisier D. Lessons learned from rheumatoid arthritis registries. Joint Bone Spine 2018;85:271-4. [https://doi. org/10.1016/j.jbspin.2017.12.005] [PMID: 29246533]

16. Lim SS, Drenkard C, McCune WJ, Helmick CG, Gordon C, Deguire $P$, et al. Population-based lupus registries: advancing our epidemiologic understanding. Arthritis Rheum 2009;61:1462-6. [https:// doi.org/10.1002/art.24835] [PMID: 19790117]

17. Flouri I, Markatseli TE, Voulgari PV, Boki KA, Papadopoulos I, Settas L, et al. Comparative effectiveness and survival of infliximab, adalimumab, and etanercept for rheumatoid arthritis patients in the Hellenic Registry of Biologics: Low rates of remission and 5-year drug survival. Semin Arthritis Rheum 2014;43:447-57. [https://doi. org/10.1016/j.semarthrit.2013.07.011] [PMID: 24012040]

18. Flouri ID, Markatseli TE, Boki KA, Papadopoulos I, Skopouli FN, Voulgari PV, et al. Comparative Analysis and Predictors of 10year Tumor Necrosis Factor Inhibitors Drug Survival in Patients with Spondyloarthritis: First-year Response Predicts Longterm Drug Persistence. J Rheumatol 2018;45:785-94. [https://doi. org/10.3899/jrheum.170477] [PMID: 29606666]

19. Glintborg B, Ostergaard M, Krogh NS, Andersen MD, Tarp U, Loft $A G$, et al. Clinical response, drug survival, and predictors thereof among 548 patients with psoriatic arthritis who switched tumor necrosis factor alpha inhibitor therapy: results from the Danish Nationwide DANBIO Registry. Arthritis Rheum 2013;65:1213-23. [https://doi.org/10.1002/art.37876] [PMID: 23460467]

20. Papalopoulos I, Fanouriakis A, Kougkas N, Flouri I, Sourvinos G, Bertsias G, et al. Liver safety of non-tumour necrosis factor inhibitors in rheumatic patients with past hepatitis B virus infection: an observational, controlled, long-term study. Clin Exp Rheumatol 2018;36:102-9. [PMID: 28850029]

21. Hochberg MC. Updating the American College of Rheumatology revised criteria for the classification of systemic lupus erythematosus. Arthritis Rheum 1997;40:1725. [https://doi.org/10.1002/ art.1780400928] [PMID: 9324032]

22. Petri M, Orbai AM, Alarcon GS, Gordon C, Merrill JT, Fortin PR, et al. Derivation and validation of the Systemic Lupus International Collaborating Clinics classification criteria for systemic lupus erythematosus. Arthritis Rheum 2012;64:2677-86. [https://doi. org/10.1002/art.34473] [PMID: 22553077] [PMCID: PMC3409311]

23. Aringer M, Costenbader K, Daikh D, Brinks R, Mosca M, Ramsey-Goldman R, et al. 2019 European League Against Rheumatism/American College of Rheumatology classification criteria for systemic lupus erythematosus. Ann Rheum Dis 2019;78:1151-9. [https://doi.org/10.1002/art.40930] [PMID: 31385462] [PMCID: PMC6827566]

24. Navarra SV, Guzman RM, Gallacher AE, Hall S, Levy RA, Jimenez RE, et al. Efficacy and safety of belimumab in patients with active systemic lupus erythematosus: a randomised, placebo-controlled, phase 3 trial. Lancet 2011;377:721-31. [https://doi.org/10.1016/ S0140-6736(10)61354-2] [PMID: 21296403]

25. Gergianaki I, Fanouriakis A, Adamichou C, Spyrou G, Mihalopoulos $\mathrm{N}$, Kazadzis S, et al. Is systemic lupus erythematosus different in urban versus rural living environment? Data from the Cretan Lupus 
Epidemiology and Surveillance Registry. Lupus 2019;28:104-13. [https://doi.org/10.1177/0961203318816820] [PMID: 30522399]

26. Gergianaki I, Fanouriakis A, Repa A, Tzanakakis M, Adamichou C, Pompieri A, et al. Epidemiology and burden of systemic lupus erythematosus in a Southern European population: data from the community-based lupus registry of Crete, Greece. Ann Rheum Dis 2017;76:1992-2000. [https://doi.org/10.1136/annrheumdis-2017-211206] [PMID: 28780511]

27. Gladman DD, Ibanez D, Urowitz MB. Systemic lupus erythematosus disease activity index 2000. J Rheumatol 2002;29:288-91. [PMID: 11838846]

28. Buyon JP, Petri MA, Kim MY, Kalunian KC, Grossman J, Hahn BH, et al. The effect of combined estrogen and progesterone hormone replacement therapy on disease activity in systemic lupus erythematosus: a randomized trial. Ann Intern Med 2005;142:953-62. [https://doi.org/10.7326/0003-4819-142-12_part_1-20050621000004] [PMID: 15968009]

29. Albrecht J, Werth VP. Development of the CLASI as an outcome instrument for cutaneous lupus erythematosus. Dermatol Ther 2007;20:93-101. [https://doi.org/10.1111/j.15298019.2007.00117.x] [PMID: 17537137]

30. Franklyn K, Lau CS, Navarra SV, Louthrenoo W, Lateef A, Hamijoyo $\mathrm{L}$, et al. Definition and initial validation of a Lupus Low Disease Activity State (LLDAS). Ann Rheum Dis 2016;75:1615-21. [https:// doi.org/10.1136/annrheumdis-2015-207726] [PMID: 26458737]

31. van Vollenhoven R, Voskuyl A, Bertsias G, Aranow C, Aringer M, Arnaud $L$, et al. A framework for remission in SLE: consensus findings from a large international task force on definitions of remission in SLE (DORIS). Ann Rheum Dis 2017;76:554-61. [https://doi. org/10.1136/annrheumdis-2016-209519] [PMID: 27884822]

32. Gladman D, Ginzler E, Goldsmith C, Fortin P, Liang M, Urowitz M, et al. The development and initial validation of the Systemic Lupus International Collaborating Clinics/American College of Rheumatology damage index for systemic lupus erythematosus. Arthritis Rheum 1996;39:363-9. [https://doi.org/10.1002/art.1780390303] [PMID: 8607884]

33. Fries JF, Spitz P, Kraines RG, Holman HR. Measurement of patient outcome in arthritis. Arthritis Rheum 1980;23:137-45. [https://doi. org/10.1002/art.1780230202] [PMID: 7362664]

34. England BR, Sayles H, Mikuls TR, Johnson DS, Michaud K. Validation of the rheumatic disease comorbidity index. Arthritis Care Res (Hoboken) 2015;67:865-72. [https://doi.org/10.1002/acr.22456] [PMID: 25186344] 